\title{
Screening of keto reductases expressed in conidial fungi from the Brazilian semi-arid region
}

\author{
Serly Santiago Machado ${ }^{1}$, Enesio Rodriguez Nascimento Neto ${ }^{1}$, Elisa Teshima ${ }^{1}$, \\ Osmar Calderon Sanchez ${ }^{2}$, Heiddy Marquez Alvarez ${ }^{1}$, Ivan Sergio Colás Gonzáles ${ }^{1}$ \\ Luis Fernando Pascholati Gusmão', Angélica Maria Lucchese ${ }^{1}$
}

\author{
1 Universidade Estadual de Feira de Santana, Av Transnordestina SN, Feira de Santana, Bahia, Brazil 2 \\ Universidad de la Habana. Zapata y G. CP 10400. Ciudad Habana. Cuba \\ *angelica.lucchese@gmail.com
}

Keywords: biocatalysis, acetophenone, fungi

\section{INTRODUCTION}

Chiral alcohols are key building blocks for many industrial products, such as pharmaceuticals and other high value compounds ${ }^{1}$. Although several synthetic methods for the production of chiral alcohols from ketones are known, biocatalysis is one of the most important tools because of its high chemo-, regio- and stereoselectivity, as well as mild and environmentally friendly reaction conditions ${ }^{1,2}$. Isolated keto reductases or whole-cell biological systems can be used as catalysts to this conversion, and studies seeking new sources of these enzymes have been carried out ${ }^{2}$. It is well established that the screening of a wide variety of microorganisms, which are living in our environment, is one of the methods to obtain new biocatalysts ${ }^{1,2}$. In this work some conidial fungi from the semi-arid region as biocatalysts in the reduction process of acetophenone to identified potential producers of keto reductases were evaluated.

\section{RESULTS AND DISCUSSION}

The screening for the identification of microorganisms with reductase activity was performed with 56 conidial fungi, isolated from dead plant material in Brazilian semi-arid region. Acetophenone in presence of ethanol as co-solvent was used as substrate $(0,1 \% \mathrm{v} / \mathrm{v})$, and after 5 days of incubation the products were analysed by gas chromatography coupled to mass spectrometry (GC/MS). From these fungi, 34 catalysed the bioreduction of acetophenone with conversion rates from $1 \%$ up to $55 \%$. The Prelog's rule was followed in 24 bioreduction process yielding the $S$ enantiomer preferentially, of which nine of them with a high stereoselectivity (>99\%). Ten fungi catalysed the bioreduction to the anti-Prelog $R$ product but with lower stereoselections ( $55 \%$ up to $94 \%$ ee). In table 1 the results of bioreduction with conversion rates higher than $5 \%$ are summarized.
Table 1. Assymetric reduction of acetophenone with conidia fungi

\begin{tabular}{llcc}
\hline Code & Microorganisms & C (\%) & ee (\%) \\
\hline $04 / 06$ & Sarcopodium circinatrum & 5 & $94(\mathrm{R})$ \\
$05 / 06$ & Curvularia inaequalis & 11 & $83(\mathrm{~S})$ \\
$07 / 06$ & Cladosporium sp & 32 & $86(\mathrm{R})$ \\
$21 / 06$ & Stachybotrys sp & 16 & $76(\mathrm{R})$ \\
$27 / 06$ & Aspergillus sp & 34 & $55(\mathrm{R})$ \\
$30 / 06$ & Stachybotrys sp & 35 & $67(\mathrm{R})$ \\
$35 / 06$ & Beltrania sp & 10 & $87(\mathrm{~S})$ \\
$38 / 06$ & Cladosporium sp & 7 & $79(\mathrm{~S})$ \\
$53 / 06$ & Dictyosporium sp & 18 & $>99(\mathrm{~S})$ \\
$73 / 06$ & Curvularia sp & 15 & $88(\mathrm{~S})$ \\
$82 / 06$ & Periconia sp & 43 & $>99(\mathrm{~S})$ \\
$87 / 06$ & Dictyosporium sp & 9 & $>99(\mathrm{~S})$ \\
$98 / 06$ & Idriella sp & 55 & $95(\mathrm{~S})$ \\
$101 / 06$ & Dictyochaeta sp & 44 & $90(\mathrm{~S})$ \\
$01 / 07$ & Stachybotrys sp & 9 & $83(\mathrm{~S})$ \\
$03 / 07$ & Curvularia sp & 11 & $>99(\mathrm{~S})$ \\
$12 / 07$ & Myrothecium sp & 30 & $>99(\mathrm{~S})$ \\
$16 / 07$ & Pestalotiopsis sp & 7 & $>99(\mathrm{~S})$ \\
$26 / 07$ & Stachybotrys sp & 44 & $96(\mathrm{~S})$ \\
$35 / 07$ & Stachybotrys sp & 37 & $87(\mathrm{~S})$ \\
$36 / 07$ & Pithomyces chartarum & 15 & $55(\mathrm{R})$ \\
$42 / 07$ & Periconia hispidula & 43 & $95(\mathrm{~S})$ \\
$114 / 07$ & Cladosporium sp & 12 & $82(\mathrm{~S})$ \\
\hline
\end{tabular}

${ }^{*} \mathrm{C}=$ conversion rates (CG/MS), ee = enantiomeric excess (chiral $\mathrm{CG})$, absolute configuration is in parenthesis.

\section{CONCLUSION}

New sources of keto reductases were identified. The Periconia sp 82/06 and Myrothecium sp 12/07 were the most efficient producers of keto reductases with high enantioselectivity and moderate conversions in the conditions used in this screening.

\section{ACKNOWLEDGEMENTS}

Fapesb, CNPq, MCT/PPBio

\section{REFERENCES}

${ }^{1}$ Carvalho, C.C.C.R. Biotechnology Advances, 2011, 29, 75.

${ }^{2}$ Matsuda, T.; Yamanaka, R.; Nakamura, K. Tetrahedron:

Asymmetry, 2009, 20, 513 